\title{
Family Environment Support in Early Intervention of Children with Cerebral Palsy
}

\author{
Dimas Arif Dewantoro \\ Special Education \\ State University of Malang \\ Malang, Indonesia \\ dimas.arif.fip@um.ac.id
}

\author{
Sinta Yuni Susilawati \\ Special Education \\ State University of Malang \\ Malang, Indonesia \\ sinta.yuni.fip@um.ac.id
}

\author{
Rizqi Fajar Pradipta \\ Special Education \\ State University of Malang \\ Malang, Indonesia \\ rizqi.fajar.fip@um.ac.id
}

\begin{abstract}
The aim of this study was to describe family environment support and formulate early family-based intervention program by describing the acceptance, belief, understanding, planning, and intervention of children with Cerebral Palsy (CP). The study used a qualitative descriptive method and involved a family who had twins experiencing CP. The study found that the family had confidence and were not overprotective of $\mathrm{H}$ and $\mathrm{N}$, the extended family accepted the conditions of their children and committed to optimizing their development, parents had an understanding of the ability and disability of $H$ and $\mathbf{N}$ but did not understand the special needs of each child and how to fulfill it. Through interdisciplinary facilitation, the family was able to understand, design, and fulfill the special needs of $H$ and $N$ based on their characteristics.
\end{abstract}

Keywords - early intervention with family resources, children with cerebral palsy.

\section{INTRODUCTION}

Cerebral palsy (CP) children have problems in physical and motor development due to abnormalities in the central nervous system (brain). $\mathrm{CP}$ is a common problem, the worldwide incidence being 2 to 2.5 per 1000 live births [1]. Mental retardation (MR) is common in CP in up to $60 \%$ of the cases. The study in India reports MR in $72.5 \%$ of affected children. Children with spastic quadriplegia have a greater degree of cognitive impairment than children with spastic hemiplegia. Speech is affected in CP due to bilateral corticobulbar and or motor dysfunctions. Both receptive and expressive language deficits are common and go hand-inhand with mental retardation. Articulation disorders and impaired speech are present in 38\% children with CP [2].

According to the location of abnormalities in the brain and the function of the motion of the cerebral palsy is divided into: (1) spastic, with characteristics such as there is stiffness in some or all of the muscle; (2) dyskinesia, which includes athetosis (the patient shows uncontrolled motion), rigid (stiffness in the whole body so that it is difficult to bend); tremor (continuous small vibrations in the eyes, hands or on the head); (3) Ataxia (there is a balance disorder, the road is mutilated, eye and hand coordination is not functioning; and (4) the type of mixture (a child has two or more abnormalities of the types above). According to the motor impairment of the global motor functions (GMFCS I to $\mathrm{V})$; and according to anatomical distribution, unilateral (monoprotic, hemiparetic) and bilateral (diparetic, triparetic, quadriparetic). Whereas according to the degree of disability, cerebral palsy is classified as (1) mild, with traits, which can walk without aids, speak clearly, and can help themselves; (2) medium, with features: requires help to practice speaking, walking, taking care of yourself, and special tools, such as brace; and (3) profound, with traits, which requires constant care in ambulation, speech, and self-help.

Children born with $\mathrm{CP}$ are more likely to have some learning disabilities, which may be related or unrelated to their IQ. Different children are likely to manifest different degrees of intellectual ability that varies from genius to intellectual impairment [3]. Further, it is advisable to not ignore or underestimate the capabilities of $\mathrm{CP}$ children, they should be given every opportunity available to learn [4]. Family ecology, therapists have identified three determinants as influential in the acquisition of motor abilities for children with $\mathrm{CP}$ including family support to the child, family expectations of motor performance, and support available to the family [5]. Family functioning related to relationship, organization, expectations, and support to each other and to their $\mathrm{CP}$ child.

The fact that family plays an important role in the lives of children with disabilities is a view that has increasingly gained importance. Family education level, sociocultural status, and psychological approach of parents play an important role in the development of children with CP [6]. The profile of the family needs of children with $\mathrm{CP}$ and information on the factors affecting these requirements are very limited [7]. These children show marked differences in terms of the development of gross motor function and its final status, and the needs of families markedly vary on the basis of these functions. Lack of awareness on resources and their distribution issues cause serious problems in patients with CP. Determination of the overall needs of families and the determination of its relation according to the child's age, family income, gross motor function, and dexterity classification assist families and healthcare professionals in determining goals and ensuring the coordination of services [8].

This study was conducted on families who have achieved success in caring for twins of cerebral palsy, $\mathrm{H}$ and $\mathrm{N}$. $\mathrm{H}$ is categorized as severe $\mathrm{CP}$ who have a relatively low intellectual level. With his disabilities, he can develop and has non-academic achievements. Whereas $\mathrm{N}$ is categorized as moderate CP which has a relatively moderate intellectual level. With his disabilities, he can develop and have academic and non-academic achievements. Based on family experience, various support is given, early intervention is believed to be the most credible foundation for child development. 


\section{METHOD}

To obtain objective data, accurate and valid, then the study was conducted with the descriptive qualitative approach. The main background is the case in families who have twin cerebral palsy children. Through observation, hopefully, this will provide an overview of family environment support and early intervention formulations. The researcher as a research instrument, the gathering is done by observation, interview, and documentation study. Participants in this study are a parent, $\mathrm{H}$ and N. Parents early intervention program has been implemented to optimize the development of their twins. Data obtained by describing the achievements of children's achievement and intervention efforts in children with cerebral palsy by family.

\section{FINDINGS AND DISCUSSION}

\section{A. Findings}

Based on the data collected, the following information about $\mathrm{H}$ and $\mathrm{N}$ profiles and family environment support.

\section{1) Profile $H$}

Based on the data, it was found that $\mathrm{H}$ was 10 years old and had CP from birth. He was born normally, the baby cries at birth. Medical diagnosis says $\mathrm{H}$ has $\mathrm{CP}$ at 2 years old. Information on motoric development is carried through unstructured assessments and observations. It is known that the ability of $\mathrm{H}$ is not able to do walking, running, jumping, standing on one leg, and others. Both his legs and right hand suffered paralysis. In addition, he showed spasticity. The findings show that $\mathrm{He}$ can be classified as a child with $\mathrm{CP}$ triplegia in spastic. He has relatively small gross motor skills, as well as its fine motoric abilities. He can only move the fingers of his left hand. In his daily activities, he does with the help of others. Some activities cannot be done such as moving places with or without a wheelchair, wearing clothes, taking care of his self, and so on. As for the main capital in developing its potential, H's ability to operate the gadget by moving his finger.

Information about cognitive abilities is obtained from assessment of cognitive development and unstructured observation. It is known that the ability of $\mathrm{H}$ cognitively to compare objects based on size, sort objects from up to the largest have been able to do. clinical results mention $\mathrm{H}$ has 90 IQ. the conclusion is that $\mathrm{H}$ needs the special needs education according to their cognitive abilities.

Information about Language and Speech, $\mathrm{H}$ shows speech development that is relatively slow due to the difficulty in moving the speech organs. However, the development of language is comparable to children of his age. The role of early intervention is very important for language development, such as speech therapy, physiotherapy and educational treatment. The achievement in academic ability is the ability to read. The other achievements are the ability to tell stories. His accustomed to telling stories using verbal even though the sentence is not smooth. In addition, he can make stories using a specially modified gadget for him.

\section{2) Profile $N$}

Based on the data, it was found that $\mathrm{N}$ was 10 years old and had CP from birth. He was born normally, the baby cries at birth. Medical diagnosis says $\mathrm{N}$ has $\mathrm{CP}$ at 2 years old. Information on motoric development is carried out through unstructured assessments and observations. It is known that the ability of $\mathrm{H}$ is not able to do walking, running, jumping, standing on one leg, and others. Both legs experience paralysis. So that $\mathrm{N}$ can be classified as a child with $\mathrm{CP}$ paraplegia. $\mathrm{N}$ has relatively good gross motor skills, as well as fine motoric abilities. He cannot move both legs but can move both hands well. In his daily activities, he does it independently. Some activities can be done such as moving places using a wheelchair, wearing clothes, taking care of his self, write by hand, etc. The main capital owned is proficient in moving his hands. Based on the assessment of cognitive development in an unstructured manner, it is known that the cognitive abilities of $\mathrm{N}$ are normal like a common child. The skills mastered include reading, describing and analyzing concepts. Clinical results mention $\mathrm{N}$ has $118 \mathrm{IQ}$. The conclusion is the need to learn is like a child in general.

Information on Language and Speech, N shows good speech development. Similarly with the comparable development of language in his age. Achievements in language development and speech are singing achievements, and debate competitions. The achievement of $\mathrm{N}$ in academic ability is the ability to read, write and analyze. Other achievements are singing achievements and debating competition achievements. In addition, $\mathrm{N}$ has adaptive sports achievements such as running fast using a wheelchair.

\section{3) Family Roles}

The family has a very big influence on child development, because the family is the closest environment to the child. $\mathrm{H}$ and N's parents have made several efforts to develop their children's best. The following findings in the role of the family are Family Environment Scale (FES), Family Expectations of Child (FEC), and Family Support for Child (FSC).

Family Environment Scale (FES). $\mathrm{H}$ and $\mathrm{N}$ are twins and have an older sister. Their father, mother, and sister show good acceptance of their disability. The family relationship is very good, the father who works in the medical field has built a harmonious relationship with the division of tasks towards the development of the potential of $\mathrm{H}$ and $\mathrm{N}$. In addition, there are several family activities such as recreation, worship together and spend time together. There is a special time for families to teach $\mathrm{H}$ and $\mathrm{N}$ in the academic and non-academic fields.

Family Expectations of Child (FEC), parents have said that expectations for $\mathrm{H}$ and $\mathrm{N}$ are realistic and optimistic. Medical and psychological diagnosis describes the factual condition of their child. In addition, recommendations for treatments for academic and non-academic development have been given. The family strives to do the best for $\mathrm{H}$ and $\mathrm{N}$. Some approaches are carried out through medical, psychological and educational roles.

Family Support for Child (FSC), various support has been sought by the family, including physical and psychological support. Interventions are carried out with medical, psychological and educational approaches by related experts through therapy. Like speech therapy, physiotherapy, and psychological therapy. Besides that, the family also practically intervenes directly. There is a special time for the family to provide interventions to develop academic and non-academic abilities $\mathrm{H}$ and $\mathrm{N}$. Interventions made based on program recommendations by experts. The 
program is prepared based on the results of the ability assessment of $\mathrm{H}$ and $\mathrm{N}$.

TABLE I. FAMILY SUPPORT TO CHILD WITH CEREBRAL PALSY

\begin{tabular}{|c|c|c|}
\hline \multirow[t]{2}{*}{ Aspect } & \multicolumn{2}{|c|}{ Implementation of the Intervention Program } \\
\hline & $\mathbf{H}$ & $\mathbf{N}$ \\
\hline Motoric & $\begin{array}{l}\text { Physiotherapy, is a } \\
\text { priority in gross and } \\
\text { fine motoric abilities. } \\
\text { The realistic goal is to } \\
\text { rehabilitate hand } \\
\text { functions to carry out } \\
\text { daily activities } \\
\text { Daily activities } \\
\text { adapted to the activity } \\
\text { needs, such as eating, } \\
\text { toileting, writing, etc. }\end{array}$ & $\begin{array}{l}\text { - Physiotherapy is still } \\
\text { done. Optimizing foot } \\
\text { function } \\
\text { - Motor development in } \\
\text { adaptive sports skills }\end{array}$ \\
\hline Language & $\begin{array}{l}\text { The main focus on } \\
\text { expressive language. } \\
\text { Through verbal and } \\
\text { visual (symbol) } \\
\text { Assistive technology is } \\
\text { provided using a } \\
\text { gadget }\end{array}$ & $\begin{array}{l}\text { Language development } \\
\text { is relatively good }\end{array}$ \\
\hline Communication & $\begin{array}{l}\text { Speech therapy is done } \\
\text { consistently }\end{array}$ & $\begin{array}{l}\text { The development of } \\
\text { communication is } \\
\text { relatively good }\end{array}$ \\
\hline Cognitive & $\begin{array}{l}\text { The program focuses } \\
\text { on the ability to } \\
\text { remembering and } \\
\text { reading }\end{array}$ & $\begin{array}{l}\text { Cognitive development } \\
\text { is relatively good }\end{array}$ \\
\hline $\begin{array}{l}\text { Talent } \\
\text { Development } \\
\text { and Interest } \\
\text { Program }\end{array}$ & $\begin{array}{l}\text { Development of verbal } \\
\text { and non-verbal } \\
\text { storytelling skills }\end{array}$ & $\begin{array}{l}\text { - Development of } \\
\text { academic potential } \\
\text { - Development of non- } \\
\text { academic potential } \\
\text { (singing, co-debate } \\
\text { and adaptive sports) }\end{array}$ \\
\hline
\end{tabular}

\section{B. Discussion}

The results of this study indicate that there are different abilities in twins with cerebral palsy. The family has an important role in the development of CP children ability. The role of the family is illustrated through the Family Environment Scale (FES), Family Expectations of Child (FEC), and Family Support to Child (FSC).

Family Environment Scale (FES), acceptance of disability of twins children is relatively good. Both children were identified as cerebral palsy children since 2 years of age. Good acceptance is shown by the family harmonization between the father, mother, older sister and CP twins. Harmony reflects the amount of care given by the family. The FES contains 90 true/false statements that represent three dimensions and 10 subscales of family functioning: relationships (cohesion, expressiveness and conflict), personal growth (independence, achievement orientation, intellectual/cultural orientation, active/recreational orientation and moral/religious emphasis), and system maintenance (organization and control) [9]. in line with the opinion, CP person need care from parents, doctors, speech therapists, occupational therapists, caregivers, and other medical practitioners or specialists are involved in managing different aspects of the disorder [10].

Family Expectations of Children are built in a realistic manner according to the ability of CP children. The FEC contains five items on expectations parents have of their children to: (1) do the best that they can, (2) assist in taking care of themselves, (3) try everything, (4) do activities recommended by their child's therapists, and (5) do all regular family activities [11]. Some approaches are carried out through medical, psychological and educational roles. Parents, doctors, speech therapists, occupational therapists, caregivers, and other medical practitioners or specialists are involved in managing different aspects of the disorder [12]. The complexity of the disorder and the treatment efforts introduces many challenges in the management of CP. A comprehensive management program should begin after diagnosis [13].

Family Support for Child (FSC). The support provided in the form of intervention programs on aspects of motoric, language, communication and cognitive. $\mathrm{H}$ with $\mathrm{CP}$ spastic triplegia, the intervention in the motoric aspect is physiotherapy that is adjusted to the needs of daily activities. Intervention in the aspect of language is emphasized on the development of expressive language that is supported by assistive technology, interventions in communication development prioritized in speech therapy, intervention in the cognitive aspects prioritized in the development of basic academic abilities, and the development of talent in verbal and non-verbal storytelling skills. $\mathrm{N}$ with spastic $\mathrm{CP}$ paraplegia, intervention in the motoric aspect is physiotherapy based on adaptive sports skills, relatively good language and cognitive development, and development of interest talents in academic and non-academic potential. The FSC contains six items on the supports that families provide to their children in fostering their development. The items are: (1) encouraging independence, (2) encouraging risktaking, (3) offering encouragement and recognizing accomplishments, (4) engaging in enjoyable and energetic physical play, (5) involving many people who regularly interact with the child in therapy activities throughout the day,and (6) responding positively to the child's interests [11].

$\mathrm{CP}$ person needs the care to complete activities such as carrying, lifting, dressing, bathing, play, feeding and communication [14]. Such help is important to ensure that the patients improve interactions and enjoy as much a normal life as possible. In addition, they need caregiver support for administration of medication and the use of special devices such as splints, braces \& casts for improving support and motor capabilities [15]. If such specialized devices are available to $\mathrm{CP}$ person who do not have caregivers to administer them, these powerful supportive devices may not have any impact on their lives.

\section{CONCLUSION}

There are several efforts that can be given to children with CP. Although twins, needs, and treatments should be given according to their characteristics. The high complexity of the CP disorder and its treatment introduces many challenges into the management process. Families are encouraged to share information about their daily lives, resources, support, and priorities to assist therapists in individualizing supports and interventions. Family ecology, including family strengths, expectations, interests, supports, and resources, should be discussed and families should be actively involved when developing interventions and supports for young children with $\mathrm{CP}$ and their families.

\section{REFERENCES}

[1] Rosen MG, Dickinson JC. The incidence of cerebral palsy. Am J Obstet Gynecol 1992; 167: 417-423. 
[2] Gregory, S., et al., Health status of children with moderate to severe cerebral palsy. Developmental Medicine \& Child Neurology, 2001. 43(6): p. 364-370. Neil, M., et al., Neurologic and Developmental Disability at Six Years of Age after Extremely Preterm Birth. N Engl J Med, 2005. 352(14): p. 9- 19.

[3] Michael, O., Diagnosis, Treatment, and Prevention of Cerebral Palsy in Near-Term/Term Infants. Clin Obstet Gynecol, 2008. 51(4): p. 816-828.

[4] Bartlett, D. J. \& Palisano, R. J. (2002) Physical therapists' perceptions of factors influencing the acquisition of motor abilities of children with cerebral palsy: implications for clinical reasoning. Physical Therapy, 82, 237-2

[5] Aydın R, Nur H. Cerebral Palsili Çocukların Tedavisinde Aile Odakl Yaklaşım. Turk J Phys Med Rehab 2012;58:229-35

[6] Palisano R, Almarsi N, Chiarello L, Orlin M, Bagley A, Maggs J. Family needs of parents of children and youth with cerebral palsy. Child Care Health Dev 2010;36:85-92.

[7] Almasri N, Palisano R, Dunst C, Chiarello LA, O’Neil M, Polansky M. Profiles of family needs of children and youth with cerebral palsy. Child Care Health Dev 2012;38:798-806
[8] Moos, R. \& Moos, B. (2002) A Social Climate Scale: Family Environment Scale Manual - Development, Application, Research, 3rd edn. Midgarden Inc., Palo Alta, CA, USA.

[9] Keith, M., A report: the definition and classification of cerebral palsy April 2006. Developmental Medicine \& Child Neurology, 2006. 49(109): p. 8-14.

[10] A, LaForme FIss. Family Ecology of Young Children with Cerebral Palsy. Child Care Health and Development. 2013; p.1-10

[11] Dinah, S., et al., Journal of Intellectual and Developmental Disability. Social outcomes of young adults with cerebral palsy, 2013. 38(3): p. 215-222.

[12] Krigger, K., Cerebral Palsy: An Overview. American Family Physician, 2006. 73(1): p. 91-100.

[13] Ann-Christin, E. and K. Lena, The Manual Ability Classification System (MACS) for children with cerebral palsy: scale development and evidence of validity and reliability. Developmental Medicine \& Child Neurology, 2006. 2(7): p. 549-554.

[14] Ellen, W. and R. Peter, The Gross Motor Function Classification System for Cerebral Palsy: a study of reliability and stability over time. Developmental Medicine \& Child Neurology, 2007. 42(5): p. 292-296. 